Tropical Journal of Pharmaceutical Research June 2012; 11 (3): 469-475

(C) Pharmacotherapy Group,

Faculty of Pharmacy, University of Benin

Benin City, 300001 Nigeria.

All rights reserved.

Available online at http://www.tjpr.org

Research Article

http://dx.doi.org/10.4314/tjpr.v11i3.17

\title{
Two Novel Non-Conventional Seed Oil Extracts with Antioxidant and Antimicrobial Activities
}

\author{
Lessoy T Zoué ${ }^{1}$, Micaël E Bédikou ${ }^{1}$, Jean T Gonnety ${ }^{2}$, Betty M Faulet ${ }^{2}$ \\ and Sébastien L Niamké ${ }^{1^{*}}$ \\ ${ }^{1}$ Laboratoire de Biotechnologies, Filière Biochimie-Microbiologie de I'Unité de Formation et de Recherche en \\ Biosciences de l'Université de Cocody-Abidjan, 22 BP 582 Abidjan, ${ }^{2}$ Laboratoire de Biochimie et Technologie des \\ Aliments de l'Unité de Formation et de Recherche en Sciences et Technologie des Aliments de l'Université d'Abobo- \\ Adjamé, 02 BP 801 Abidjan 02, Côte d'lvoire.
}

\begin{abstract}
Purpose: To investigate the seed oils of Corchorus olitorius and Hibiscus sabdariffa for their antioxidant and antimicrobial potential.

Methods: The physicochemical characteristics of oil of the plant seeds were determined using standard methods while their volatile compounds were analyzed by gas chromatography coupled with mass spectrometery (GC-MS). The antioxidant activity of these oils was determined using 2,2-Diphenyl-1picrylhydrazyl (DPPH) free radical scavenging method, and their antimicrobial effect was determined by agar dilution method.

Results: Phospholipids, carotenoids and phenols contents of the studied seed oils were approximately $2.0 \%, 100 \mathrm{mg} / 100 \mathrm{~g}$ and $6.7 \mathrm{mg} / 100 \mathrm{~g}$, respectively. GC-MS analysis of the volatile compounds showed the presence of various aromatic and aliphatic organic compounds while the antioxidant activity of the oils was in the range of 0 to $5 \mathrm{~g} / \mathrm{l}$, which was higher than that of ascorbic acid. The seed oils also showed antimicrobial activity against Staphylococcus aureus, Aspergillus fumigatus and Trichophyton mentagrophytes with minimal inhibitory concentrations (MIC) of 250.0 and $62.5 \mathrm{mg} / \mathrm{ml}$ for C. olitorius and $H$. sabdariffa seed oils, respectively.

Conclusion: $C$. olitorius and $H$. sabdariffa seed oils showed pronounced antioxidant and antimicrobial activities. These characteristics should be exploited for possible applications in the food supplement, pharmaceutical and cosmetic industries.
\end{abstract}

Keywords: Corchorus olitorius, Hibiscus sabdariffa, Seed oil, Antioxidant activity, Antimicrobial activity 


\section{INTRODUCTION}

Many oils for human consumption or for industrial purposes are derived from plants. The conventional plant oils are mostly represented by palm (Elaeis guinensis) oil, olive (Olea europaea) oil, soybean (Glycine max) oil and sunflower (Helianthus annuus) oil. These oils consist mainly of mono-, diand tri-acylglycerols which act as solvent for minor constituents such as sterols, fat-soluble vitamins, pigments including chlorophylls and carotenoids, phenolic compounds, phospholipids and free fatty acids [1]. These minor constituents can have either prooxidative (e.g., free fatty acids and hydroperoxides) or antioxidant (e.g., tocopherols, pigments, phenols and phospholipids) effects [2].

Antioxidant compounds are gaining in importance due to their dual role in food and pharmaceutical industries as lipid stabilizers [3]. Nutritionally important antioxidants such as tocopherols improve the stability of oils [4]. Phenolic compounds may prevent deterioration through the quenching of reactions responsible for lipid rancidity [5]. Moreover, the higher antioxidant activity of some crude oils is partly due to polar lipids, especially phospholipids. Indeed, these compounds are usually considered free radical scavengers, antioxidant synergists and extenders for the action of primary antioxidants [6]. With regard carotenoids, it is accepted that they can act as primary antioxidants by trapping free radicals or as secondary antioxidants by quenching singlet oxygen [7].

Besides the antioxidant effect of these minor constituents of plant oils, another beneficial property is their antimicrobial activity. Indeed, this activity is due to the volatile components isolated from essential oil fractions [8]. Recent studies showed that some nonconventional seed oils such as Nigella sativa, Coriandrum sativum and Guizotia abyssinica seed oils contain essential fatty acids, antioxidants and antimicrobial constituents with high nutritional, pharmaceutical and cosmetic properties [9].

Corchorus olitorius and Hibiscus sabdariffa belong to the families of Tiliaceae and Malvaceae, respectively. In most countries of tropical Africa and particularly in Côte d'Ivoire, the leaves of these plants are widely consumed as green vegetables but their seeds are under-exploited. Indeed, some reports have revealed the antioxidant and antimicrobial activities of the leaves and flowers of these two tropical plants $[10,11]$. However, there is no report dealing with the antioxidant and antimicrobial activities of the seed oils of the two plants. Therefore, the aim of this work was to investigate the possible antioxidant and antimicrobial activities of these seed oils.

\section{EXPERIMENTAL}

\section{Plant materials}

C. olitorius and $H$. sabdariffa seeds were collected from Abidjan district (Côte d'Ivoire) in June 2009. The plants were identified and authenticated by Professor Ake Assi (Botany Department of Cocody University - Abidjan). Voucher specimens (nos. AMPT04 and ABAN 07S, respectively) of the plants were kept in the herbarium of National Center of Agronomic Research (CNRA) of Côte d'Ivoire. The seeds were washed thoroughly with distilled water to remove dirt and dried at $40{ }^{\circ} \mathrm{C}$ for $24 \mathrm{~h}$ in an electric oven (Memmert, Germany).

\section{Chemicals}

Analytical grade solvents, standards, reagents and culture media were used to perform the study. Organic solvents, butylated hydroxyl toluene (BHT), 2,2Diphenyl-1- picrylhydrazyl (DPPH) and FolinCiocalteu's phenol reagent were obtained from Merck. All reference standards used were from Sigma-Aldrich. Culture media (Sabouraud agar and Mueller-Hinton agar) were manufactured by Bio-Mérieux. 


\section{Extraction of oil from the seeds}

Oils were extracted from the powdered seeds $(50 \mathrm{~g})$ of the respective plants with $300 \mathrm{ml}$ of n-hexane by Soxhlet method. The solvent was gently evaporated at $40{ }^{\circ} \mathrm{C}$ from the extract solution on a rotary evaporator (Heidolph, Hei-Vap, Germany) to dryness, and the oil weighed, and stored at $4{ }^{\circ} \mathrm{C}$ in airtight brown sterile glass bottles prior to analysis.

\section{Fractionation of lipids}

One gram $(1 \mathrm{~g})$ of oil in $15 \mathrm{ml}$ of chloroform was fractionated into neutral lipids, glycolipids and phospholipids by column chromatography [3]. The oil sample was placed onto a column $(2 \mathrm{~cm} \times 30 \mathrm{~cm})$ containing activated silica gel (100-200 mesh). Lipid fractions were recovered by sequential elution at a flow rate of $2 \mathrm{ml}$ per min with three times the column volume of chloroform, four times the column volume of methanol and five times the column volume of acetone to separate neutral lipids (NL), phospholipids (PL) and glycolipids (GL), respectively. The different solvents were evaporated at $40{ }^{\circ} \mathrm{C}$ with a rotary evaporator (Heidolph, Hei-Vap, Germany) under vacuum, and each lipid fraction was weighed and expressed as percentage of total lipids. Each lipid fraction was identified and classified on a $F_{254}$ silica gel TLC plate (Merck, Germany) by comparison with frontal references $\left(R_{f}\right)$ of standards. The TLC plates were run with hexane-diethyl ether-acetic acid in the proportion of 80:20:2 (v/v/v) and spots developed in iodine vapour for $5 \mathrm{~min}$. Lipid colours were brown after developing spots.

\section{Determination of carotenoid and total phenol contents}

The carotenoid content of the oils was determined by measuring the absorbance of hexanic oil solution at $450 \mathrm{~nm}$ using a UV-Vis spectrophotometer (T80+, PG Instruments, UK). Different quantities (varying from 0 to 2 $\mathrm{mg}$ ) of $\beta$-carotene were used as standards. Total phenols were extracted four times with $10 \mathrm{ml}$ of methanol-water $(80: 20, \mathrm{v} / \mathrm{N})$ mixture by centrifugation at $1000 \mathrm{rpm}$ for $10 \mathrm{~min}$. Total phenols were quantified by FolinCiocalteu colorimetric method, using gallic acid (ranging from 0 to $1 \mathrm{mg}$ ) as standards.

\section{Determination of antioxidant activity}

The antioxidant activity of the oils was determined using the DPPH method [12]. Approx. of DPPH in isooctane $(0.1 \mathrm{mM}$ solution) was prepared and $1 \mathrm{ml}$ of this solution was added to $5 \mathrm{ml}$ of the oil in isooctane to give concentrations ranging from $0-5 \mathrm{~g} / \mathrm{l}$. The same procedure was used with standard antioxidants (BHT, $\alpha$-tocopherol and ascorbic acid). It was left to stand for $30 \mathrm{~min}$ in a dark place and the absorbance of the samples measured at $517 \mathrm{~nm}$ using a UV-Vis spectrophotometer (T80+, PG instruments, UK). The inhibition of DPPH radical was calculated using Eq 1.

Inhibition $(\%)=\left[\left(A_{0}-A\right) / A_{0}\right] \times 100$

where $A_{0}$ is the absorbance of the control and $A$ that of the test sample.

\section{Analysis of volatile compounds}

Volatile compounds were analyzed by chromatography using a gas chromatograph (Shimadzu GC-9A, Japan) equipped with a mass spectrometer (MS) and a RTX5 fused silica capillary column (30 m length, $0.32 \mathrm{~mm}$ diameter, $0.25 \mu \mathrm{m}$ film thickness coated with $95 \%$ dimethylpolysiloxane). One (1) $\mu \mathrm{l}$ of oil diluted in $\mathrm{n}$-heptane was injected into this column and the carrier gas (helium) was set at a flow rate of $23 \mathrm{ml} / \mathrm{min}$. The initial column temperature was set at $100{ }^{\circ} \mathrm{C}$, programmed to increase at an interval of $5{ }^{\circ} \mathrm{C}$ per minute until $220^{\circ} \mathrm{C}$ and then maintained for $10 \mathrm{~min}$ at this temperature. The temperature of the detector and injector was maintained at 250 ${ }^{\circ} \mathrm{C}$. The retention times of volatile constituents were compared with a computer data base of chemical compounds for identification. 
Table 1: Extraction yield and composition of Corchorus olitorius and Hibiscus sabdariffa seed oils

\begin{tabular}{lcc}
\hline \multirow{2}{*}{ Constituent } & \multicolumn{2}{c}{ Seed oil } \\
\cline { 2 - 3 } & C. olitorius & H. sabdariffa \\
\hline Extraction yield (\%) & $11.9 \pm 1.1^{\mathrm{a}}$ & $24.5 \pm 2.0^{\mathrm{b}}$ \\
Neutral lipids (\%) & $93.2 \pm 2.0^{\mathrm{a}}$ & $94.1 \pm 2.0^{\mathrm{a}}$ \\
Glycolipids (\%) & $3.7 \pm 0.7^{\mathrm{a}}$ & $2.6 \pm 0.7^{\mathrm{b}}$ \\
Phospholipids (\%) & $1.90 \pm 0.1^{\mathrm{a}}$ & $2.1 \pm 0.1^{\mathrm{a}}$ \\
Carotenoids (mg $\beta$-carotene/100 g) & $90.0 \pm 0.0^{\mathrm{a}}$ & $120.0 \pm 0.0^{\mathrm{b}}$ \\
Total phenol (mg gallic acid/100 g) & $6.9 \pm 0.0^{\mathrm{a}}$ & $6.6 \pm 0.0^{\mathrm{a}}$ \\
\hline
\end{tabular}

\section{Bacteria and fungal cultures}

Standard fungal and bacterial species were obtained from the Biotechnology Laboratory, UFR Biosciences, University of CocodyAbidjan (Côte d'Ivoire). Six fungal species, namely, Aspergillus fumigatus (896/AB), Trichophyton mentagrophytes (13801/D), Trichophyton rubrum (14301/D), Candida albicans (3076/PV), Candida tropicalis (13763/D) and Cryptococcus neoformans $(3812 / \mathrm{B})$, and three bacteria species Staphylococcus aureus (587/10), Escherichia coli $(585 / 10)$ and Pseudomonas aeruginosa $(602 / 10)$ - were used.

\section{Determination of antimicrobial activity}

Antimicrobial activity was determined using the agar dilution method. First, oil samples $(10 \mathrm{~g})$ were dissolved in $10 \mathrm{ml}$ of ethylene glycol [13]. Series of culture media at different oil concentrations (varying from 3.9 to $500 \mathrm{mg} / \mathrm{ml}$ ) were prepared. The agar culture media (Mueller-Hinton agar for bacteria and Sabouraud agar for fungi) surfaces were inoculated with $10 \mu \mathrm{l}$ of microbial inoculum $\left(10^{5} \mathrm{cells} / \mathrm{ml}\right)$ indicated above. An inoculated and incubated agar culture medium without the test oils was used as positive growth control for each assay. The plates for antibacterial activity were incubated at $37{ }^{\circ} \mathrm{C}$ for $24 \mathrm{~h}$ while those for antifungal tests were incubated at $30{ }^{\circ} \mathrm{C}$ for $72 \mathrm{~h}$. In each case, the colonies were counted using a colony counter (JP Selecta, Spain) and the minimum inhibitory concentration (MIC) of the oils determined. The MICs were determined as the lowest concentration of oil that produced no visible microbial growth after the incubation period.

\section{Statistical analysis}

Each sample was analyzed in triplicate and data are reported as mean \pm standard deviation (SD). Analysis of variance (ANOVA) was performed using StatPlus 2008 (Analystsoft Inc) software. Statistical significance was set at $p \leq 0.05$.

\section{RESULTS}

The oil yield of $H$. sabdariffa seeds was 24.5 $\pm 2.0 \%$ and that of $C$. olitorius seeds $11.9 \pm$ $1.1 \%$. The chemical composition of $C$. olitorius and $H$. sabdariffa seed oils is shown in Table 1. The fractionation of the oils revealed $93.2-94.1 \pm 2,2.6-3.7 \pm 0.7$ and $1.9-2.1 \pm 0.1 \%$ of neutral lipids, glycolipids and phospholipids, respectively. The profile of each lipid fraction is depicted by TLC plates in Figure 1. Carotenoid and total phenol contents of the oil were about $100 \pm$ $0.0 \mathrm{mg} \beta$-carotene $/ 100 \mathrm{~g}$ and $6.7 \pm 0.0 \mathrm{mg}$ gallic acid/100 g, respectively.

The antioxidant activity of the oils is depicted in Figure 2. Inhibition of DPPH at $5 \mathrm{~g} / \mathrm{l}$ was 37 $\%$ and $65 \%$ for $C$. olitorius and $H$.sabdariffa seed oils, respectively. However, at the same concentration, ascorbic acid, a-tocopherol and butylhydroxyaldehyde showed inhibition of 15,73 and $92 \%$, respectively.

Figure 3 shows the gas chromatography profiles of the volatile components of $C$. olitorius and $H$. sabdariffa seed oils. GC-MS analysis resulted in the identification of 7 volatile compounds including hydrocarbon 
aromatic acids, aliphatic unsaturated acid, aromatic ester and aliphatic unsaturated esters

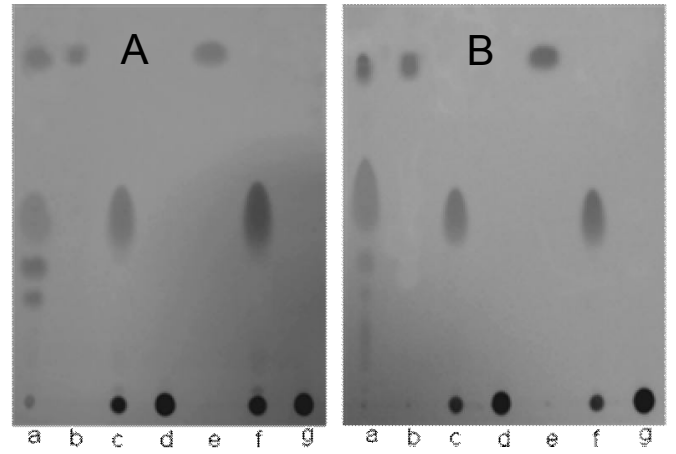

Fig 1: TLC (on $\mathrm{F}_{254}$ silica gel plate) showing different lipid fractions of (A) Corchorus olitorius and (B) Hibiscus sabdariffa seed oils. Key: (a) test oil, (b) neutral lipid standard, (c) glycolipid standard, (d) phospholipid standard, (e) neutral lipid fraction, (f) glycolipid fraction, (g) phospholipid fraction.

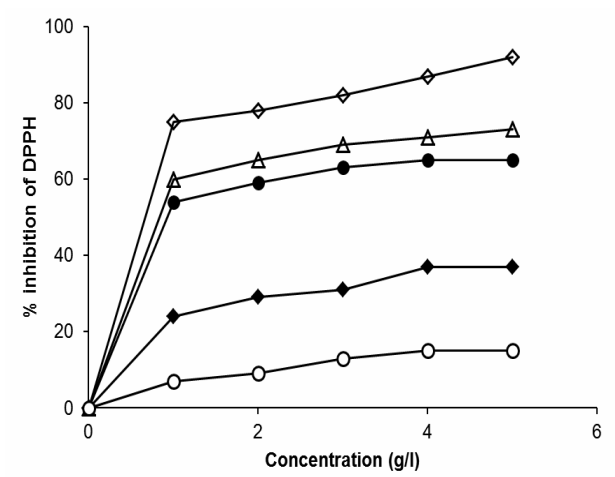

Fig 2: Comparison of the antioxidant activity of Corchorus olitorius ( $\bullet$ ) and Hibiscus sabdariffa $(\bullet)$ seed oils with that of of butylated hydroxytoluene $(\diamond)$, a-tocopherol $(\Delta)$ and ascorbic acid (o).

The antimicrobial activity of $C$. olitorius and $H$. sabdariffa seed oils is presented in Figure 4. In the concentration range of $3.9-500$ $\mathrm{mg} / \mathrm{ml}$, C. olitorius seed oil totally inhibited the growth of $S$. aureus, $A$. fumigatus and $T$. mentagrophytes (MIC, $250 \mathrm{mg} / \mathrm{ml}$ ) while $H$. sabdariffa seed oil, demonstrated total inhibition of $A$. fumigatus and $T$. mentagrophytes species with MIC of 62.5 $\mathrm{mg} / \mathrm{ml}$. All the other tested microorganisms
(Trichophyton rubrum, Candida albicans, Candida tropicalis, Cryptococcus neoformans, Escherichia coli and Pseudomonas aeruginosa) were resistant to the two oils in the concentration range of 3.9 to $500 \mathrm{mg} / \mathrm{ml}$ (data not shown).

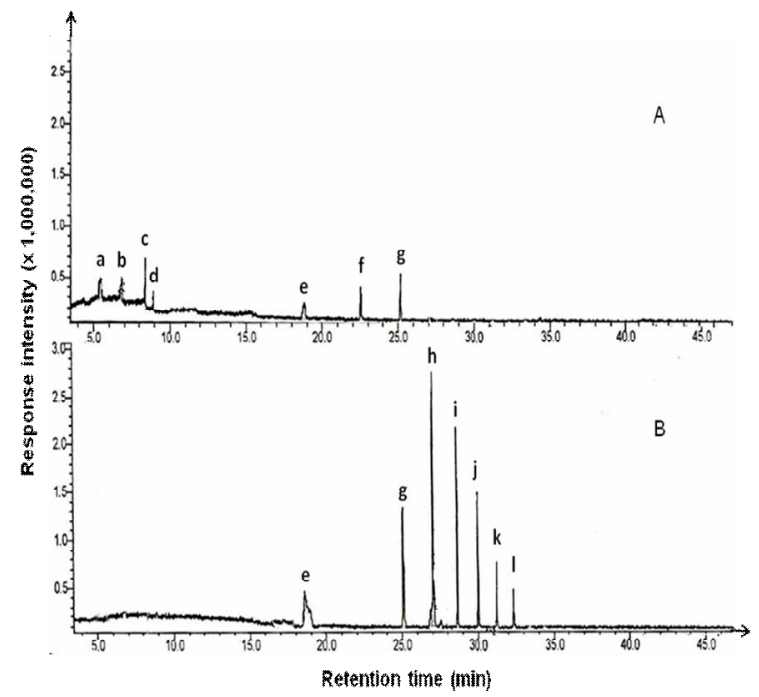

Fig 3: Chromatograms of volatile components of (A) Corchorus olitorius and (B) Hibiscus sabdariffa seed oils. Key: (a) octasiloxane, (b) 2Dodecenedioic acid, (c) ethylphtalate, (d) benzoic acid, (e) benzeneacetic acid, (f) 1H-Purin-6-amine, (g) eicosamethylcyclodecasiloxane, (h) phosphine imide, (i) 2-Fluorophenylmethyl, (j) monocarbonyl1,3-butadiene-1,4-dicarbonic acid diethyl ester, and (k) eicosamethyl, (I) 1,4-butadiene.

\section{DISCUSSION}

In terms of their oil content, the seeds of $H$. sabdariffa are richer in lipids than most wellknown seed oils such as those derived from cotton (13\%), soybean (14\%), and palm fruit (20\%) [14]. Therefore, the tests seeds could be explored as alternative sources of oils for industrial purposes.

The lipid profile seed oils indicate that they are good sources of phospholipids the levels of which compare favourably with that of soybean oil (1.5 to $2.5 \%$ ) [15]. This high level of phospholipids may contribute to the stability and antioxidant activity of the oils. 
Test oils are richer in carotenoids than expensive oils such as niger (Guizotia abyssinica) seed oil (70.2 $\pm 0.03 \mathrm{mg} \beta$ carotene/100 g) and coriander (Coriandrum sativum) seed oil $(89.2 \pm 0.05 \mathrm{mg} \beta$ carotene/100 g) [16]. Carotenoids are important ingredients in cosmetic industries due to their antioxidant activity and protective effect on the skin [17]. Thus, in this respect, the test oils could find use in the cosmetic industry.
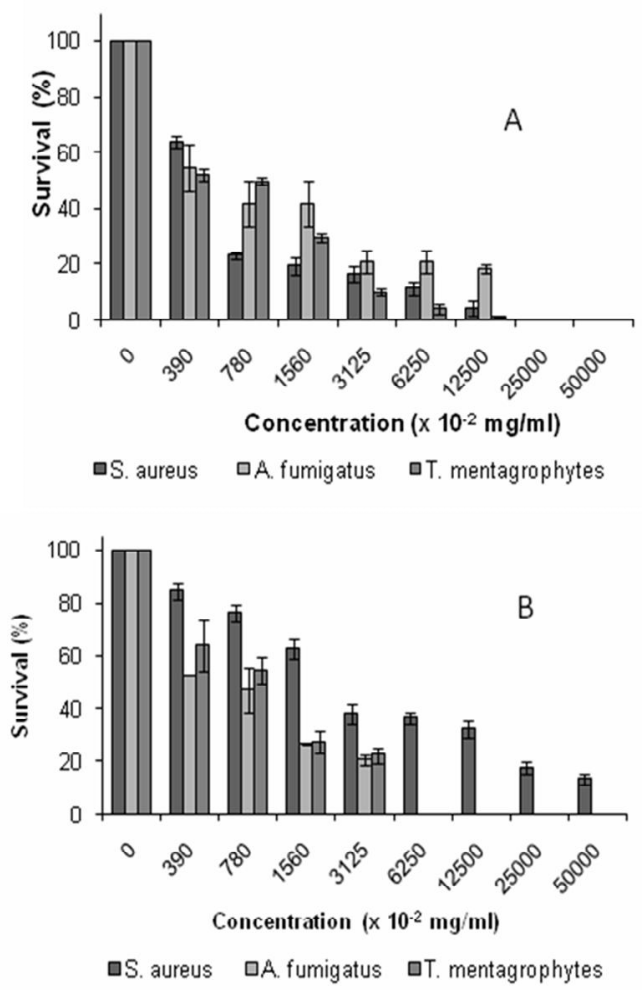

Fig 4: Antibacterial and antifungal activities of $(A)$ Corchorus olitorius and (B) Hibiscus sabdariffa seed oils against $S$. aureus, $A$. fumigatus and $T$. mentagrophytes

Total phenol content of the test oils is lower than that reported for olive oil which is in the range of 10 to $30 \mathrm{mg} / 100 \mathrm{~g}$ [15]. Nevertheless, the oils are richer in phenolic compounds than other oils such as that of pumpkin seeds $(3.9 \pm 2.6 \mathrm{mg} / 100 \mathrm{~g})$ [18]. These compounds have previously been correlated with the oxidative stability of vegetable oils. As a result, the relatively high concentration of phenolic compounds in the studied seed oils is a great asset for their use as stabilizers in the food and cosmetic industries.

Antioxidant activity decreased in the order: BHT $>$ a-tocopherol $>H$. sabdariffa seed oil $>$ C. olitorius seed oil $>$ ascorbic acid. Therefore, the extracted oils could be suitable as antioxidant additives to preserve fatty foods and skin care products against oxidative deterioration [3].

With regard to the identified volatile components, $C$.olitorius and $H$. sabdariffa seed oils cannot be categorized as essential oils. Essential oils are natural mixtures of phytochemicals originating from two distinctive groups. The first group comprises of terpenes and terpenoids and the other, of aromatic and aliphatic constituents [19]. Nevertheless, the test oils could be used as substitutes for essential oil due to their richness in volatile components.

Although $C$. olitorius seed oil showed both antibacterial and antifungal activities, $H$. sabdariffa seed oil is a stronger inhibitor of microbial growth based on MIC data. The antibacterial and antifungal activities of the test oils are worthy of note because fixed oils which are mainly used as diluents for essential oils, usually do not show significant antimicrobial activity [20]. The antimicrobial activity of the two test oils may probably be due to the identified volatile aromatic constituents [8]. Consequently, the oils could be used as antifungal agents for skin care products since $A$. fumigatus, $T$. mentagrophytes and $S$. aureus are mostly involved in superficial infections of the skin.

\section{CONCLUSION}

The high content of carotenoids, phosphorlipids and total phenol, confer on $C$. olitorius and $H$. sabdariffa seed oils higher antioxidant activity than other well-known and high-value 
oils. Their antioxidant activity is also superior to that of ascorbic acid. Furthermore, the oils have the potential to be used in antimicrobial therapy against $S$. aureus, $A$. fumigatus and T. mentagrophytes which are usually involved in skin mycosis. Consequently, seeds of $C$. olitorius and $H$. sabdariffa are potential new sources of high-value oils with pharmaceutical, cosmetic and nutritional applications.

\section{ACKNOWLEDGEMENT}

This work was supported by a $\mathrm{PhD}$ grant to the first author. The authors are grateful to the National Laboratory of Animal Nutrition and Dietetics (LANADA), Abidjan-Côte d'Ivoire, for technical assistance.

\section{REFERENCES}

1. Kamal-Eldin A. Minor components in vegetable oils. In: Shahidi F. editors. Industrial fats and oils, edible oil and fat products: Specialty oils and oil products. Vol. 3. Chichester: John Wiley and Sons; 2005; pp 319-359.

2. Tasioula-Margari $M$, Okogeri $O$. Isolation and characterization of virgin olive oil phenolic compounds by HPLC/UV and GC-MS. J Food Sci 2001; 66: 530-534.

3. Ramadan MF, Morsel JT. Screening of the antiradical action of vegetable oils. J Food Compos Anal 2006; 19: 838-842.

4. Warner K, Frankel EN. Effect of $\beta$-carotene on light stability of soybean oil. J Am Oil Chem Soc 1987; 64: 213-218.

5. Cai R, Hettiarachchy NS, Jalaluddin M. Highperformance liquid chromatography determination of phenolic constituents in 17 varieties of cowpeas. J Agr Food Chem 2003; 51: 1623-1627.

6. Hildebrand DH, Terao J, Kito M. Phospholipids plus tocopherols increase soybean oil stability. J Am Oil Chem Soc 1984; 61: 552-555.

7. Reische DW, Lillard DA, Eintenmiller $R R$. Antioxidants. In: Akoh C.C. editors. Food lipids. $2^{\text {nd }}$ ed. New York: Marcel Dekker; 2002; pp 489-516.
8. Carson CF, Riley TV. Antimicrobial activity of the major components of the essential oil of Melaleuca alternifolia. J Appl Bacteriol 1995; 78: 264-269.

9. Ujjwal N, Ruchi S, Rashmi KM, Raju KC. Lipid content and in vitro antimicrobial activity of oil seeds of some Indian medicinal plants. Curr Res Bacteriol 2008; 1: 1-6.

10. Ali BH, Al-Wabel N. Blunden G. Phytochemical, pharmocological and toxicological aspects of Hibiscus sabdariffa L.: A review. Phytother Res 2005; 19: 369-375.

11. Khan MSY, Bano S, Javed K, Mueed M. A comprehensive on the chemistry and pharmacology of Corchorus species- $A$ source of cardiac glycosides, triterpenoids, ionones, flavonoids, coumarins, steroids and some other compounds. J Sci Ind Res 2005; 65: 283-298.

12. Blois MS. Antioxidant determination by the use of a stable free radical. Nature 1958; 181: 1199 1200.

13. Salman MT, Khan RA, Shukla I. Antimicrobial activity of Nigella sativa Linn. seed oil against multidrug resistant bacteria from clinical isolates. Nat Prod Rad 2008; 7: 10-14.

14. Nzikou JM, Mvoula-Tsieri M, Matos L, Matouba E, Ngakegni-Limbili AC, Linder M, Desobry $S$. Solanum nigrum $L$. seeds as an alternative source of edible lipids and nutriment in CongoBrazzaville. J Appl Sci 2007; 7: 1107-1115.

15. Gunstone DF. Vegetable oils in food technology: Composition, properties and uses. London: Blackwell Publishing Ltd; 2002. 337pp.

16. Ramadan MF, Mörsel JT. Oxidative stability of black cumin (Nigella sativa L.), coriander (Coriandrum sativum L.) and niger (Guizotia abyssinica Cass.) crude seed oils upon stripping. Eur J Lipid Sci Technol 2004; 106: 35-43.

17. Platon JF. Lipids in cosmetology. Ol. Corps Gras Lipid 1997; 4: 275-281.

18. Andjelkovic M, Camp JV, Trawka A, Verhe R. Phenolic compounds and some quality parameters of pumpkin seed oil. Eur J Lipid Sci Technol 2010; 112: 208-217.

19. Bakkali $F$, Averbeck S, Averbeck D, Idaomar $M$. Biological effects of essential oils- $A$ review. Food Chem Toxicol 2008; 46: 446-475.

20. Hammer KA, Carson CF, Riley TV. Antimicrobial activity of essential and other plant extracts. $J$ Appl Microbiol 1999; 86: 985-990. 